\title{
UM PESSIMISTA CONVICTO NA MINHA EQUIPE: ESTILOS DE LIDERANÇA E MOTIVAÇÃO
}

\section{A CONVICTED PESSIMIST IN MY TEAM: LEADERSHIP STYLES AND MOTIVATION}

\author{
FRANCINE LUCATELLI \\ Universidade do Vale do Itajaí (UNIVALI) \\ Mestre em Administração - UNIVALI \\ Orcid: http://orcid.org/0000-0002-8339-7239 \\ E-mail:fran_lucatelli@univali.br
}

Rua Aníbal César, 20, Apto. 404, Bairro: São Judas, Itajaí - SC, CEP: 88303-510

\section{JOÃO ANSELMO TORMEN-FERREIRA}

Universidade do Vale do Itajaí (UNIVALI)

Mestrando do Programa de Mestrado Profissional em Administração - UNIVALI

Orcid: http://orcid.org/0000-0002-3122-5654

E-mail: contato@tormen.com.br

\section{ANETE ALBERTON}

Universidade do Vale do Itajaí (UNIVALI)

Doutora em Engenharia da Produção - Universidade Federal de Santa Catarina (UFSC)

Orcid: http://orcid.org/0000-0002-6477-0122

E-mail: anete@univali.br

\section{SIDNEI VIEIRA MARINHO}

Universidade do Vale do Itajaí (UNIVALI)

Doutor em Engenharia da Produção - Universidade Federal de Santa Catarina (UFSC)

Orcid: http://orcid.org/0000-0003-0396-5898

E-mail: sidnei@univali.br

Submissão: 06/12/2019. Revisão: 26/10/2020. Aceite: 29/12/2020. Publicação: 24/02/2021. DOI: http://dx.doi.org/10.22277/rgo.v14i2.5242

\section{RESUMO}

O caso foi desenvolvido para estimular a discussão sobre estilos de liderança e motivação, buscando soluções possíveis para minimizar ou solucionar o dilema que envolve a gestão de pessoas. Por meio da experiência vivida por Jéssica, uma jovem líder que possui em sua equipe Luís, um colaborador com anos de empresa e um comportamento que a coloca em situações difíceis diante de sua equipe, espera-se que os estudantes proponham alternativas para a situação apresentada ancoradas nas teorias de liderança e motivação. Recomenda-se a aplicação deste caso em cursos de ensino superior em nível de graduação, tecnólogo ou técnico, como os cursos de Administração, Recursos Humanos e Processos Gerenciais. Pode, ainda, ser aplicado em cursos de extensão ou treinamentos de lideranças.

Palavras-chave: Liderança. Motivação. Gestão de Pessoas. 
Um pessimista convicto na minha equipe: estilos de liderança e motivação

\begin{abstract}
The case was developed to stimulate the discussion on the style of leadership and motivation, looking for possible solutions to minimize or solve the dilemma that involves people management. Through the experience lived by Jéssica, a young leader who has Luís on her team, a collaborator with years of company and a behavior that puts her in situations prior to her team, students are expected to propose alternatives to the presented situation anchored in theories of leadership and motivation. It is recommended to apply this case in higher education courses at undergraduate, technologist or technical level, such as courses in Administration, Human Resources and Management Processes. It can also be distributed in extension courses or leadership training.
\end{abstract}

Keywords: Leadership. Motivation. People Management.

\title{
1 INTRODUÇÃO
}

É manhã de uma segunda-feira chuvosa, o despertador toca pela terceira vez e Jéssica não tem mais como prorrogar, ela precisa levantar-se e encarar mais uma semana de trabalho na Conexão Criativa, uma agência de publicidade e propaganda, que fica cerca de 15 minutos distante de sua casa, na cidade de Itajaí, litoral norte de Santa Catarina.

Jéssica iniciou sua carreira profissional na agência aos 18 anos, como estagiária. Ajudava na realização de todas as atividades do setor: revisão, criação, briefing, atendimento, prospecção de clientes, contato com a imprensa. Após 11 meses de estágio, foi efetivada para a parte de atendimento, mas continuou colaborando com todos os outros setores da agência. O dono da agência sempre apreciou muito o perfil proativo e participativo de Jéssica e, após 7 anos do início de suas atividades na agência, Jéssica é a atual líder da equipe, que conta com 6 colaboradores efetivos e um estagiário.

Atualmente, Jéssica está com 25 anos e sente que sua trajetória na empresa a preparou para entender o mercado em que trabalha, no entanto, liderar uma equipe, ainda que pequena, consiste em um grande desafio para ela.

Desafio maior se apresenta quando Jéssica lembra de Luís, um antigo colaborador da agência que integra a equipe há mais de 10 anos e que boa parte desses anos passou resolvendo assuntos pessoais ou buscando distrações ao invés de trabalhar.

Jéssica conhece o perfil de Luís desde o período em que era estagiária e nunca se pronunciou a respeito, porém, agora ela é sua gestora e teme que seu comportamento influencie os demais colaboradores da equipe. Jéssica também sabe que Luís é amigo de infância do proprietário e que sua demissão não é uma possibilidade para a agência.

Sem dúvidas, Jéssica sabe que exercer sua liderança e manter a equipe integrada e motivada para apresentar bons resultados será seu grande desafio.

\section{A CONEXÃO CRIATIVA}

Conexão Criativa é uma agência de publicidade e propaganda fundada no ano de 2003 pelo Sr. Otávio Bueno e herdada por Paulo Bueno, seu filho, desde o ano de 2007. A agência está localizada na cidade de Itajaí, litoral norte de Santa Catarina e conta, em 2019, com sete colaboradores contratados para a jornada de 44 horas semanais, mais um estagiário de Comunicação que trabalha 20 horas semanais na empresa. 
Entre os principais serviços oferecidos aos clientes pela Conexão Criativa, estão: branding, campanhas de publicidade, comunicação digital, endomarketing, design, assessoria de imprensa e planejamento.

A empresa conta com um concorrente direto na cidade e três concorrentes localizados na cidade de Balneário Camboriú. Ao longo dos seus 16 anos de existência, passou por momentos de muito sucesso e grande demanda, fase em que chegou a ter em seu quadro funcional 15 colaboradores efetivos e três estagiários. Com a mudança do mercado, a agência foi enxugando a equipe e sempre prezou pela manutenção e atendimento de excelência aos clientes que possui em seu portfólio, alguns deles, juntos desde que a agência nasceu.

Durante esse período, também, a Conexão Criativa viu muitos concorrentes se estabelecerem no mercado e acabar falindo em poucos anos. Para a agência, seu diferencial consiste na credibilidade que possui por sua consolidação de mercado e no tratamento ímpar que confere aos seus clientes, muitas vezes fazendo com que a prospecção de novos clientes seja preterida em prol da excelência no atendimento aos clientes que fazem parte do portfólio.

\section{ESSA MENINA VAI LONGE!}

Jéssica nasceu em Itajaí, é filha de pais separados e sempre acreditou que seu foco e dedicação lhe proporcionariam oportunidades na carreira e na vida pessoal. $E$ foi isso que realmente aconteceu.

Desde o início abraçou sua oportunidade de primeiro emprego como estagiária da Conexão Criativa. Gostava de estar por dentro de tudo que acontecia na agência e procurava conhecer todos os setores. Era comum ouvir entre as baias a conhecida pergunta de Jéssica: "Mas, por quê?".

O tempo foi passando e, junto à Conexão Criativa, Jéssica foi se desenvolvendo. Aos poucos, as responsabilidades que ela mesmo fazia questão de assumir a credenciaram para a tão sonhada efetivação. No setor de atendimento ela conseguia conectar-se com o cliente de forma excepcional. Como tinha conhecimento em todos os setores da agência, negociava, explicava e entendia o posicionamento do cliente. Sem deixar de pensar na empresa.

"A Jéssica pensa como eu, essa menina vai longe!". Este sempre foi o pensamento do proprietário da empresa, que não precisava gastar seu latim para justificar tamanha confiança que depositava em Jéssica, afinal era visível seu desempenho e comprometimento.

Jéssica queria e tinha potencial para mais dentro da agência. Seu gestor precisava aproveitar este talento nato. Foi assim que propôs a ela a liderança da equipe logo que Aline, sua líder até então, pediu desligamento para trabalhar em outra agência. Aline cansou. Depois de anos à frente da agência, não suportava mais algumas situações comportamentais que ocorriam ali. Recebeu uma proposta interessante e não pensou duas vezes ao trocar a Conexão Criativa por sua concorrente na cidade, uma agência profissionalizada que não se percebia relações pessoais claramente influenciando tomadas de decisão organizacionais.

Jéssica topou o desafio, afinal, embora tivesse menos tempo de trabalho que alguns outros colaboradores, ela conhecia suas potencialidades e talentos, sentia-se segura porque possuía grande conhecimento sobre o mercado em que atuava, conhecia o trabalho de praticamente todas as áreas da agência e acreditava que seus colegas de trabalho percebiam seus méritos para assumir a liderança.

Ela conhecia todos muito bem e tinha um ótimo relacionamento interpessoal com a equipe por acreditar que os alinhamentos devem ser feitos em grupo, com a ajuda e o poder de decisão de todos. Porém, após sua promoção, sentiu algumas pessoas se afastarem. 
Um pessimista convicto na minha equipe: estilos de liderança e motivação

- Como uma menina que entrou esses dias na empresa pode mandar em nós?

- Quer apostar que ela vai querer que todos nós façamos as coisas do jeito dela?

Eram comentários recorrentes entre os cafés da tarde e bate-papos de corredor, sempre estimulados pelo mesmo colaborador.

A verdade é que nada disso a desanimava. Na verdade, nunca esteve tão empenhada e motivada com seu trabalho e resultados de seus esforços. Porém, começou a perceber que somente a sua motivação e engajamento não eram suficientes para as coisas acontecerem dentro da empresa. Notava que nem todos trabalhavam e davam retorno de suas responsabilidades na mesma velocidade que ela.

Os dias passavam e Jéssica começava a entender porquê Aline resmungava certos comentários entre reuniões de alinhamentos com a equipe. A verdade é que o desafio era muito maior do que ela imaginava e sem noções de gestão de pessoas e liderança, Jéssica logo percebeu a necessidade de entender mais desta área e se preparar para que os desafios que se impunham não tirassem sua própria motivação.

\section{UM PESSIMISTA ACOMODADO}

Filho único e nascido na cidade vizinha de Itajaí, Balneário Camboriú, Luís nunca fez questão de ter muitos amigos. Aluno de escola particular, conheceu Paulo, hoje proprietário da Conexão Criativa, no ensino fundamental.

Com Paulo foi diferente e rapidamente eles se tornaram amigos. A amizade dos dois se complementava: Paulo era criativo, filho de pais publicitários, influentes e conhecidos na região, gostava de falar em público e se saía muito bem nas tarefas escolares. Seu desempenho era tão bom que, de certo modo, criava certas barreiras, de inveja, em seus relacionamentos. Luís não se importava com isso. Luís era bom em cálculos, planilhas, lógica e sempre auxiliou o colega nas disciplinas exatas da escola.

Os pais de Luís incentivavam a amizade dos dois, afinal, sempre se preocuparam muito com a ausência de amizades na vida do filho, que parecia nunca se importar com isso. A verdade é que Luís sempre ganhou tudo que quis e acreditava que isso supria sua até então solidão.

No ensino médio, o assunto de escolhas profissionais tornava-se constante e Luís fugia do assunto como "diabo da cruz". Queria uma vida como de seus pais: funcionários públicos, estáveis e sem muitas preocupações. Paulo, por sua vez, sonhava em dar sequência ao trabalho de seus pais na Conexão Criativa.

Formados no ensino médio, Paulo ingressou na universidade, cursou Publicidade e Propaganda e logo emendou uma especialização fora do país. Ao retornar, em 2007, com o intuito de assumir a agência, encontrou por acaso seu amigo de infância. Luís ainda morava com os pais e, embora formado em Contabilidade, acumulava fracassos nos processos seletivos de concursos públicos.

No comando da agência, Paulo precisava realizar alguns ajustes na equipe. A colaboradora "braço direito" de seus pais no setor administrativo havia pedido desligamento. Ela iria se casar e mudar de cidade.

Tendo em vista a necessidade de confiança neste cargo, Paulo não conseguia pensar em outra pessoa que não fosse Luís. Afinal, além de ser seu único amigo de infância e confiar nele, ainda estaria ajudando o amigo desempregado desde o ensino médio.

Paulo então oficializou o convite a Luís para ser seu "braço-direito", responsabilizandose por toda a parte administrativa da Conexão Criativa. Esta não foi a melhor notícia que Luís 
gostaria de ter recebido. Mas seus pais o pressionavam para sua inserção no mercado de trabalho e então, acabou aceitando a vaga.

$\mathrm{Na}$ agência Luís não fez grandes amigos, mas no decorrer do tempo estreitou relacionamento entre os colegas, que geralmente o rodeavam para saber das novidades e acontecidos da gestão, uma vez que ele sabia tudo o que acontecia diretamente com o proprietário da agência.

O despertador sempre foi seu segundo maior inimigo, perdendo somente para a segunda-feira. Faz o que tem que ser feito, caso não consiga adiar para próximo dia. Mas às vistas de Paulo, que gerenciava seus negócios acreditando que cada colaborador deve conduzir suas atividades e decisões como acredita ser melhor, Luís é a pessoa certa no lugar certo.

As reuniões de terça-feira eram um verdadeiro combate agendado com Aline, que tomava à frente das estratégias e coordenava as atividades de toda a agência depois que Paulo começou a assumir outros negócios da família. Da mesma forma, Luís acompanhou todo o desenvolvimento de Jéssica na empresa e participou da reunião em que ela foi empossada como nova líder da equipe.

Seu rosto falava muito sobre a sua opinião referente ao fato. Entre olhos virados para cima e risadas de canto de boca, Luís cochichava com os demais, instigando apostas de quanto tempo Jéssica iria "durar" no cargo.

Com perfis bem diferentes, Jéssica e Luís nunca foram próximos. Muito mais por opção dele do que dela, que teve várias frustradas investidas de parceria de trabalho. Agora, com a liderança na mão, Jéssica trabalhava diretamente com Luís que deveria tornar-se seu braço direito também.

\section{O DESAFIO DA LIDERANÇA}

- Não vai dar certo.

- Eu avisei que ia dar errado.

Estas frases ecoavam nas reuniões de terça-feira na Conexão Criativa, acompanhadas das famosas risadas de canto de boca de Luís. E como efeito "bola de neve" se espalhavam por corredores e pelo dia a dia dos colaboradores da agência.

O desafio de Jéssica, mais que garantir a qualidade dos serviços, prezar pela excelência no atendimento e prospecção de novas parcerias e clientes, era fazer que o clima da empresa não desmoronasse frente a um possível "câncer organizacional" diagnosticado, de ciência de todos e sem perspectivas de cura.

Trabalhos realizados pela metade, dados lançados erroneamente faziam parte do dia a dia de trabalho de Luís que não disfarçava seu posicionamento de "tanto faz" quando questionado:

- Errei, devo ter copiado o número errado. Depois eu refaço e te encaminho por e-mail.

- Era visível a ausência de engajamento dele e como isso contagiava o clima da agência.

- Mas se o Paulo pode chegar todo dia atrasado, por que eu não posso?

Jéssica entendia que precisava tratar este problema de forma pontual para não perder credibilidade e engajamento com o restante da equipe. Por algumas ocasiões tentou conversar com Paulo em reuniões estratégicas sobre as situações corriqueiras que enfrentava com este colaborador e a resposta geralmente era: "Conversamos sobre isso na próxima reunião".

A ausência de métricas e clareamento das atividades de Luís eram dificuldades constantes para Jéssica, tendo em vista que ela não conseguia expor exatamente os GAPs 
devido a informações maquiadas e a ele não permitir que ela tivesse acesso ao seu trabalho. Mas esse não era o ponto crítico.

Informações vazadas de reuniões estratégicas, boatos falsos e a carga negativa e pessimista impostas por Luís no dia a dia da empresa faziam os colaboradores não entender porquê aquela pessoa ainda fazia parte da equipe e fazia Jéssica temer, também, que a credibilidade do seu trabalho estivesse ameaçada, pois um de seus liderados agia daquela forma e parecia que ela nada fazia para resolver o problema.

Ela era uma jovem líder sem vasta experiência de mercado, mas munida de muita dedicação à empresa, sabia que precisava utilizar de estratégias para minimizar ou eliminar este problema na sua equipe. Mas como fazer isso, sabendo do apreço que seu chefe tinha por Luís? O pior de tudo é que ela começava a sentir os efeitos de Luís em sua própria motivação, era cada vez mais frequente os dias em que Jéssica acordava desejando ficar em casa. Como sempre prezou muito pelos compromissos que assume, mesmo nesses dias, sempre fez o possível para que sua equipe não notasse suas eventuais desmotivações, mas ela começava a se perguntar até quando aguentaria aquela situação.

\section{NOTAS DE ENSINO}

\subsection{OBJETIVOS EDUCACIONAIS E UTILIZAÇÃO RECOMENDADA}

O caso foi desenvolvido para proporcionar aos estudantes a discussão das variáveis constantes na gestão do dia a dia organizacional, principalmente tratando dos assuntos de liderança e motivação em gestão de pessoas. Por meio da leitura e discussão do caso, esperase que os estudantes desenvolvam as habilidades de interpretação, análise de cenário, identificação de teorias clássicas e capacidade de sugerir soluções para resolução do dilema.

O caso é recomendado para as disciplinas de Fundamentos de Gestão de Pessoas, Gestão por Competências, Liderança e Motivação, em cursos de ensino superior em nível de graduação, tecnólogo ou técnico, como os cursos de Administração, Recursos Humanos e Processos Gerenciais. Pode, ainda, ser aplicado em cursos de extensão ou treinamentos de lideranças.

Quando aplicado a alunos com alguma experiência em liderança, o caso não obriga leitura prévia sobre o assunto. $\mathrm{Na}$ ausência de conhecimento empírico, sugere-se leitura prévia sobre as teorias de motivação e estilos de liderança, permitindo assim que o caso seja utilizado como instrumento didático de reflexão em torno dos assuntos e da aplicabilidade de teoria previamente apresentada para resolução do caso.

Ao considerar o cubo de dificuldade para aplicação de um caso apresentado por Leenders, Mauffette-Leenders e Erskine (2001), que se entende que o desafio educacional de um caso pode ser analisado em três dimensões, com graduações 1, 2 e 3 em cada dimensão, esse caso apresenta grau de dificuldade 2.2.1, respectivamente, nas dimensões analítica, conceitual e de apresentação.

Dimensão Analítica - refere-se ao nível de análise solicitado. Esse caso apresenta graduação 2 nessa dimensão, pois o problema do caso é facilmente identificado, porém, não há apresentação de soluções ou de possíveis caminhos a seguir no texto do caso, cabendo ao leitor apresentar as soluções possíveis.

Dimensão Conceitual - refere-se à complexidade do conceito ou técnica abordada no caso. Nessa dimensão, esse caso apresenta grau de dificuldade 2. Embora não integre questões de diferentes áreas da Administração, mantendo o foco na temática da motivação e 
liderança em gestão de pessoas, faz-se necessário compreender e lançar mão de diferentes teorias relacionadas ao assunto para propor soluções.

Dimensão de Apresentação - refere-se à quantidade, qualidade, tipo e forma de apresentação das informações. Esse caso para ensino enquadra-se no grau 1 de dificuldade para essa dimensão, pois apresenta-se de forma curta, com texto claro e objetivo e praticamente todas as informações são relevantes, sem necessidade de filtro por parte do leitor para identificar quais são as informações importantes para a resolução do caso e quais seriam as informações desnecessárias no texto.

\subsection{ALTERNATIVAS PARA ANÁLISE DO CASO}

Apresenta-se, na sequência, sugestões aos docentes para aplicação e análise desse caso, considerando dois cenários:

Cenário 1 - Alunos de cursos técnicos, tecnólogos e de graduação, sem experiência com liderança.

1. O professor poderá sugerir leituras específicas relacionadas aos assuntos do caso: liderança e motivação em gestão de pessoas, informando que fará uma avaliação sem consulta sobre as leituras solicitadas;

2. Em sala, ao invés de ir direto à avaliação, o professor entrega o caso aos alunos e oferece 30 minutos para a leitura;

3. Passado o tempo estabelecido, o professor abre a discussão do caso solicitando que os próprios alunos relacionem o caso às leituras realizadas para a aula, fazendo o paralelo com as teorias e aproveitando esse momento para tirar as dúvidas relacionadas às leituras;

É importante ressaltar que nesse primeiro momento, o professor não exige a resolução do caso, a ideia é que o caso seja aproveitado para fixar as teorias estudadas, sem que os alunos se preocupem em oferecer soluções ao dilema.

4. Após esse processo de discussão das teorias relacionadas ao caso para ensino, sugerese aplicar o questionário apresentado no Apêndice 1, de forma individual. Não é necessário que os alunos identifiquem os questionários, precisam apenas responde-lo e terão 25 minutos para isso;

5. Passado o tempo estabelecido, o professor recolherá os questionários e redistribuirá aos alunos aleatoriamente, ou seja, cada aluno receberá um questionário com respostas de outro colega que ele não sabe quem é;

6. Em seguida, inicia-se a discussão das respostas no grande grupo;

Como os alunos não estarão lendo as suas respostas pessoais às questões, espera-se que isso os deixem mais seguros para participar da aula sem "medo de errar". O questionário só possui a primeira questão fechada, com resposta exata, que pode ser corrigida por todos, as demais questões não possuem "resposta certa" e o professor pode iniciar solicitando a participação voluntária dos alunos para a leitura das respostas, caso haja alunos pouco participativos, o professor pode ir direcionamento algumas perguntas para integrar esses alunos à discussão. Por meio das respostas, o professor volta a discutir as teorias e aproveita o momento para reforçar e fixar o conteúdo.

7. Após a aplicação dos passos descritos, espera-se que os alunos tenham obtido e fixado os conhecimentos teóricos, bem como amadurecido as reflexões em torno do assunto e, agora sim, o professor propõe a retomada do caso para resolução do dilema, propondo a mesma atividade que sugere-se aplicar ao Cenário 2. 
Cenário 2 - Cursos de extensão ou treinamento de lideranças.

Nos casos em que existe conhecimento empírico em torno do dilema, sugere-se não solicitar leitura prévia em torno do assunto, nem antecipar a leitura do caso. O professor poderá dividir a turma em dois grupos e entregar o caso para leitura, oferecendo aos grupos 30 minutos para leitura e discussão do caso. Passado o tempo estipulado, sugere-se ao professor conduzir os trabalhos da seguinte forma:

1. Cada grupo receberá o desenho de uma Pirâmide (Apêndice 2) e, juntos, deverão preenchê-la identificando personagens e situações que se relacionam com as necessidades de motivação de Maslow;

2. Em seguida, um grupo se colocará no papel de Luís e deverá apontar as possíveis razões pelas quais ele age da forma apresentada, também deverá relacionar quais ações poderiam levar Luís a se sentir motivado e, consequentemente, mudar seu comportamento;

3. O outro grupo deverá apontar quais atitudes de Jéssica têm sido acertadas como líder e quais atitudes ela deve rever ou passar a adotar para melhorar o relacionamento com Luís;

4. Os grupos terão 30 minutos para discussão e preparação das respostas;

5. Passado esse tempo, o professor conduzirá a discussão entre os grupos, verificando quais os apontamentos comuns em ambos os grupos que poderiam convergir para mudanças no comportamento tanto de Jéssica quanto de Luís e quais respostas poderiam não provocar efeitos no comportamento do outro, fazendo essas anotações no quadro para visualização de toda a turma;

6. Após ter obtido algum diagnóstico sobre os personagens Luís e Jéssica com base nas constatações dos alunos, o professor passará a fazer o "link" das respostas com a teoria relacionada aos estilos de liderança e motivação em gestão de pessoas.

\section{TESTE DE APLICAÇÃO DO CASO}

Esse caso foi testado pelos autores em uma turma de 5ำ período do curso de Gestão de Recursos Humanos de uma universidade catarinense e, também, em um Treinamento de Desenvolvimento de Liderança Tática com líderes de produção de uma empresa de grande porte. Dessa forma, ambos os cenários propostos puderam ser testados. Um aspecto relevante identificado nas aplicações é que o caso pode ser utilizado para discutir e apresentar teoria a respeito de liderança formal e informal, embora não tenha sido o foco desse trabalho.

\section{FONTES DE DADOS}

As informações utilizadas na construção deste caso possuem elementos ficcionais baseados nas experiências profissionais dos autores com situações semelhantes. Os nomes dos personagens e a empresa são fictícios. Nesse sentido, a obtenção das informações se deu por meio de experiências reais dos autores, relatos, interações e análises de fatos similares aos descritos nesse caso.

\section{QUESTÕES PARA DISCUSSÃO}

1. Considerando a situação de Jéssica e a relação dela com Luís e com os demais colaboradores, e em consonância com a teoria sobre os estilos de liderança, quais as ações que Jéssica poderia adotar para conduzir à minimização ou resolução deste dilema?

2. Quais evidências comportamentais podem situar os personagens do caso na Hierarquia das Necessidades de Maslow? 
3. Com base nas informações que você possui, relacione o perfil de cada personagem com a Teoria dos Dois Fatores formulada por Herzberg, buscando identificar quais elementos têm causado satisfação ou insatisfação nos personagens.

4. Considerando suas experiências pessoais e profissionais, que ações você acredita que Luís espera de Jéssica?

\section{HÁ UM ESTILO CERTO DE LIDERAR?}

Apesar de "liderança" ser um termo amplamente discutido nos dias de hoje e ainda consistir em um campo complexo (PUTRA; CHO, 2019), cabe ressaltar que Maquiavel, na obra "O Príncipe", promovia discussões em torno do assunto (TURANO; CAVAZOTTE, 2016), direcionando para a forma que o líder deveria se comportar e com os primeiros estudos concentrados mais sistematicamente na identificação de características de figuras importantes que deveriam servir de modelo para o treinamento de novos líderes (OLIVEIRA et al., 2015).

De acordo com Policarpo e Borges (2016, p. 89) "estudiosos da psicologia social e do comportamento humano tentam há décadas descobrir quais os fatores que conduzem algumas pessoas à boa liderança e quais fatores que determinam sua aceitação".

$\mathrm{Na}$ literatura, o conceito tem evoluído com o tempo e são incontáveis os autores e pesquisadores que se dedicam a tratar do assunto. Avolio et al. (2009) afirmam que o campo de estudos em liderança não está mais focado apenas no líder, mas também nos seguidores, colegas, supervisores, ambiente de trabalho e cultura, o que inclui um conjunto muito mais amplo de indivíduos que compõem o campo de estudos.

Com base nas diversas definições encontradas, pode-se considerar que, no contexto organizacional, liderança é entendida como um conjunto de comportamentos que possibilitam ao gestor influenciar sua equipe (FONSECA; PORTO; BORGES-ANDRADE, 2015). Para que isso ocorra, os gestores podem lançar mão de diferentes métodos ou estratégias que acreditem ser úteis para a obtenção das metas e resultados pretendidos.

A decisão pela melhor forma de exercer a liderança tende a ser algo pessoal, pautado naquilo que a pessoa entende como a melhor maneira de se gerenciar as informações, os fluxos de trabalho e as pessoas. Também pode estar relacionada às habilidades que o líder precisa mostrar, ou ao estilo adotado em função do foco que oferece às suas atividades, processos ou às pessoas (GONÇALVES; MOTA, 2011). Com base no foco individual de cada um, é possível observar diferentes estilos de liderança.

Quadro 1 - Comparativo dos Estilos de Liderança às características dos personagens

\begin{tabular}{|c|c|c|c|c|}
\hline $\begin{array}{l}\text { Estilos de } \\
\text { Liderança }\end{array}$ & $\begin{array}{l}\text { Definição dos estilos } \\
\text { de liderança baseada } \\
\text { no estudo de Kurt } \\
\text { Lewin (1951) }\end{array}$ & $\begin{array}{l}\text { Em que contexto se } \\
\text { identifica este estilo de } \\
\text { liderança no Caso para } \\
\text { Ensino? }\end{array}$ & $\begin{array}{l}\text { À qual } \\
\text { personagem } \\
\text { do Caso } \\
\text { refere-se este } \\
\text { estilo? }\end{array}$ & $\begin{array}{l}\text { Pontos fortes do } \\
\text { trecho } \\
\text { relacionado ao } \\
\text { Estilo de } \\
\text { Liderança }\end{array}$ \\
\hline $\begin{array}{l}\text { Liderança } \\
\text { autocrática }\end{array}$ & $\begin{array}{l}\text { Em que o poder é } \\
\text { centralizado no líder, } \\
\text { que toma todas as } \\
\text { decisões e as impõe } \\
\text { aos colaboradores, } \\
\text { que devem acatar sem } \\
\text { questionar. }\end{array}$ & & & \\
\hline $\begin{array}{l}\text { Liderança } \\
\text { liberal }\end{array}$ & $\begin{array}{l}\text { O que dá total } \\
\text { liberdade aos } \\
\text { colaboradores, }\end{array}$ & $\begin{array}{l}\text { "Mas às vistas de Paulo, } \\
\text { que gerenciava seus } \\
\text { negócios acreditando que }\end{array}$ & Paulo & $\begin{array}{l}\text { Permite total } \\
\text { liberdade para a } \\
\text { tomada de }\end{array}$ \\
\hline
\end{tabular}


Um pessimista convicto na minha equipe: estilos de liderança e motivação

\begin{tabular}{|c|c|c|c|c|}
\hline & $\begin{array}{l}\text { exercendo } \\
\text { participação mínima } \\
\text { nas decisões da } \\
\text { equipe, ou regulando } \\
\text { as ações do grupo. }\end{array}$ & $\begin{array}{l}\text { cada colaborador deve } \\
\text { conduzir suas atividades e } \\
\text { decisões como acredita ser } \\
\text { melhor, Luís é a pessoa } \\
\text { certa no lugar certo". }\end{array}$ & & $\begin{array}{l}\text { decisões } \\
\text { individuais ou em } \\
\text { grupo; } \\
\text { Participa apenas } \\
\text { nos casos em que } \\
\text { é solicitado; } \\
\text { Omite-se a } \\
\text { problemas do dia } \\
\text { a dia; }\end{array}$ \\
\hline $\begin{array}{l}\text { Liderança } \\
\text { democrática }\end{array}$ & $\begin{array}{l}\text { O líder esboça suas } \\
\text { ideias e as expõe aos } \\
\text { colaboradores, } \\
\text { incentivando todos a } \\
\text { participarem das } \\
\text { decisões, conduzindo } \\
\text { e orientando a equipe. }\end{array}$ & $\begin{array}{l}\text { "Ela conhecia todos muito } \\
\text { bem e tinha um ótimo } \\
\text { relacionamento } \\
\text { interpessoal com a equipe } \\
\text { por acreditar que os } \\
\text { alinhamentos devem ser } \\
\text { feitos em grupo, com a } \\
\text { ajuda e o poder de decisão } \\
\text { de todos". }\end{array}$ & Jéssica & $\begin{array}{l}\text { É bastante } \\
\text { comunicativa; } \\
\text { Encoraja a } \\
\text { participação das } \\
\text { pessoas; } \\
\text { Se preocupa tanto } \\
\text { com o trabalho } \\
\text { como com o } \\
\text { grupo; } \\
\text { Atua como uma } \\
\text { facilitadora para } \\
\text { orientar seus } \\
\text { colaboradores; } \\
\text { Sugere ideias. }\end{array}$ \\
\hline
\end{tabular}

Fonte: elaborado pelos autores (2019).

Por meio do Quadro 1, observa-se com clareza os dois estilos de liderança distintos adotados pelos personagens do caso, além de se observar as definições de cada estilo, que podem auxiliar a resolução das questões 2, 3, 4 e 5 do Apêndice 1 . Considerando a personagem Jéssica, o Quadro 1 apresenta vários pontos fortes do seu estilo que, ao serem utilizados, podem auxiliar a própria líder na minimização do dilema, podendo servir de suporte à questão 02 das Notas de Ensino.

Isso não quer dizer, porém, que em determinadas situações Jéssica e Paulo não possam adotar comportamentos enquadrados em outros estilos de liderança, mesmo havendo um estilo predominante.

Hersey, Angelini e Carakushansky (1982) classificam isso como liderança situacional, e afirmam que, independentemente dos estilos de liderança (autocrático, democrático ou liberal), todos são eficazes, desde que sejam adequados ao potencial do colaborador. De acordo com Sousa e Rocha (2019), na liderança situacional busca-se encontrar uma correspondência entre o líder e a situação, ou seja, entende-se que o líder precisa ajudar sua equipe a encontrar o caminho para atingir seus objetivos. Em outras palavras, poderíamos dizer que o desafio está em fazer o correto diagnóstico do colaborador e, a partir daí, saber aplicar a ele o estilo de liderança que proporcionará os melhores resultados de acordo com cada situação.

Castro e Silva (2017) também chamam esse modelo de abordagem situacional e corroboram essa visão afirmando que é preciso que o líder tenha um diagnóstico de seus liderados, bem como flexibilidade e parceria para poder adaptar-se a eles e, com isso, contribuir, incentivar e mostrar o caminho que deve ser seguido.

Dessa forma, se Jéssica adotar o estilo de liderança ou abordagem situacional, ela apresentará estilos de liderança diferentes, muito mais voltados para a situação e para as pessoas com as quais ela está se relacionando do que apenas pautados em suas próprias características pessoais. Isso porque, de acordo com Gonçalves e Mota (2011, p. 408), “o estilo 
de liderança que um gerente deve utilizar para influenciar um indivíduo ou equipe vai depender do nível de maturidade destes últimos".

Ainda com base nas autoras, a liderança situacional consiste em uma tentativa para adaptar um estilo de liderança específico às circunstâncias externas (nesse caso, o comportamento de Luís), pois na liderança situacional entende-se que um tipo de liderança será eficaz em determinada situação, porém, um tipo de liderança diferente poderá ser mais eficaz em outra.

É possível, por exemplo, que o estilo de liderança democrático de Jéssica aplicado a todos os seus colaboradores, inclusive Luís, não traga resultados tão positivos para ela e para a agência. Possivelmente um estilo de liderança diferente para um colaborador com comportamento e anseios diferentes, apresentará melhores resultados.

\section{OS INCOMODADOS SE RETIRAM OU SE TRANSFORMAM?}

A máxima "os incomodados que se retirem" é, também, muitas vezes aplicada ao ambiente organizacional, especialmente nas situações que envolvem profissionais acomodados e desmotivados, que buscam fazer o mínimo possível sem necessidade de algum esforço por melhorias pessoais ou coletivas, como o perfil de Luís, por exemplo, que na confiança de ter sua estabilidade profissional garantida, acredita que se alguém está incomodado com seu comportamento, isso não é problema dele.

Nesse caso, o problema então seria de Jéssica, que se incomoda com a situação e ainda não gostaria de "se retirar" como fez Aline, mas sim resolver ou, ao menos minimizar os problemas com Luís. Na visão de Reis et al. (2018), a globalização promoveu mudanças que têm permitido transformar os colaboradores que antes eram passivos e cumpridores de tarefas rotineiras em profissionais ativos em seu desenvolvimento pessoal, porém, para que isso ocorra, "novos líderes são os protagonistas das mudanças" pois "sabem lidar e resolver problemas com sua equipe de trabalho" (REIS et al., 2018, p. 129).

Considerando esse olhar, percebe-se a responsabilidade que os líderes possuem no gerenciamento e promoção de mudanças em suas equipes, ainda que em uma visão mais simplista, o problema esteja no perfil de um dos colaboradores e não na líder.

Para Dias e Borges (2015, p. 203) "as equipes são uma unidade básica de desempenho, sendo necessário mobilizá-las para que trabalhem efetivamente em equipe e, assim, consigam gerar os resultados almejados". Considerando que o grande responsável por essa mobilização é o líder, recai novamente sobre Jéssica a responsabilidade de buscar alternativas para minimizar os problemas com Luís e, por consequência, conseguir mobilizar toda a equipe para o alcance dos resultados.

Ao olhar para os estilos de liderança apresentados na seção anterior e confrontar a teoria com o dilema desse caso, é possível inferir que a solução ou minimização do problema está muito mais condicionada à expertise de Jéssica de saber utilizar melhor seu estilo de liderança em prol do alcance do seu objetivo de melhorar o comportamento de Luís do que da própria vontade de Luís, que não apresenta indícios de melhoria.

Quando Dias e Borges (2015, p. 207) afirmam que "considerando o âmbito de atuação de uma liderança, é possível avaliar a influência do seu estilo tanto em nível individual, quanto em nível de equipe", fica claro que o estilo de liderança possui influência individual sobre os liderados e uma vez que isso ocorra, entende-se que um estilo de liderança padrão aplicado a todos os indivíduos obterá resultados diferentes, pois as necessidades, expectativas e anseios de cada colaborador são diferentes. Por esse motivo sugere-se que o estilo de liderança situacional seja mais indicado para Jéssica, no sentido de que ela possa transitar entre os 
Um pessimista convicto na minha equipe: estilos de liderança e motivação

estilos apresentados de acordo com o perfil, previamente diagnosticado por ela, de cada colaborador.

Ao restringir o diagnóstico apenas ao perfil de Luís, que é o colaborador que tem influenciado de forma negativa o comportamento da equipe, e considerar a adoção do estilo de liderança situacional por parte de Jéssica, propõe-se algumas alternativas para auxiliar a atuação de Jéssica, conforme apresenta-se no Quadro 2.

Quadro 2 - Proposta de ações com base no Estilo de Liderança Situacional para Jéssica, considerando o perfil de Luís

\begin{tabular}{|c|c|c|}
\hline $\begin{array}{c}\text { Ao utilizar o } \\
\text { estilo de... }\end{array}$ & Jéssica pode... & Com isso, espera-se que... \\
\hline $\begin{array}{l}\text { Liderança } \\
\text { autocrática }\end{array}$ & $\begin{array}{l}\text { Impor metas (previamente aprovadas } \\
\text { por Paulo); } \\
\text { Exigir a apresentação dos relatórios } \\
\text { mensais para acompanhar e enviar ao } \\
\text { Paulo; } \\
\text { Estabelecer métricas para } \\
\text { acompanhamento de desempenho } \\
\text { individual. }\end{array}$ & $\begin{array}{l}\text { Jéssica consolide sua imagem de líder ao ter } \\
\text { sua proposta respaldada pelo dono da } \\
\text { empresa (Luís não poderá questionar); } \\
\text { Luís seja direcionado à realização das suas } \\
\text { atividades, uma vez que não é 'apenas' } \\
\text { Jéssica que está pedindo; } \\
\text { Luís passe a desempenhar suas atividades } \\
\text { sem tanta procrastinação, com receio de que } \\
\text { sua negligência profissional passe a ser } \\
\text { diagnosticada e mensurada. }\end{array}$ \\
\hline $\begin{array}{l}\text { Liderança } \\
\text { liberal }\end{array}$ & $\begin{array}{l}\text { Solicitar um projeto de melhoria para a } \\
\text { agência onde Luís será o único } \\
\text { responsável } \\
\text { Delegar decisões do dia a dia ao próprio } \\
\text { Luís. }\end{array}$ & $\begin{array}{l}\text { Luís sinta-se reconhecido e motivado a } \\
\text { implementar algo novo que poderá ajudá-lo } \\
\text { a encontrar motivos para mudar seu } \\
\text { comportamento profissional. } \\
\text { Luís perceba a responsabilidade e as } \\
\text { consequências dos atos dele. }\end{array}$ \\
\hline $\begin{array}{l}\text { Liderança } \\
\text { democrática }\end{array}$ & $\begin{array}{l}\text { Elogiar as evoluções de resultado e } \\
\text { comportamento de Luís, mesmo que } \\
\text { ainda esteja aquém do que ela espera; } \\
\text { Propor desafios e recompensas; } \\
\text { Realizar reuniões periódicas para discutir } \\
\text { o andamento das atividades em curso. } \\
\text { Atrair e envolver a equipe - } \\
\text { principalmente Luís - nas decisões e } \\
\text { normas da empresa. }\end{array}$ & $\begin{array}{l}\text { Luís sinta-se reconhecido e motivado a } \\
\text { melhorar seu desempenho; } \\
\text { Luís sinta-se motivado a alcançar as metas } \\
\text { para ser recompensado; } \\
\text { Luís sinta-se na obrigação de realizar suas } \\
\text { atividades para ter o que expor aos seus } \\
\text { colegas durante as reuniões. } \\
\text { A equipe, que está aos poucos se } \\
\text { desmotivando, se reaproxime de Jéssica e ela } \\
\text { conquista a confiança destes novamente. }\end{array}$ \\
\hline
\end{tabular}

Fonte: elaborado pelos autores (2019).

O Quadro 2, além de oferecer suporte para responder à questão para discussão 02 , também permite observar que há diversas ações que Jéssica pode propor objetivando melhorar o comportamento de Luís. Muito embora, de acordo com a teoria e o perfil pessoal de Jéssica, ela tenha sido diagnosticada como uma líder democrática, diante da falta de efetividade das suas ações frente ao dilema, torna-se importante que Jéssica considere implementar outras ações menos características de sua personalidade, porém, possivelmente, mais eficientes para minimização do seu problema organizacional.

\section{O QUE TE MOTIVA?}

Motivação é sempre um assunto muito debatido nas organizações. Quais as causas da motivação? Quem é o responsável por motivar? Por quais razões motivar? O que me motiva?

Haeckl, Sausgruber e Tyran (2018) afirmam que é importante, tanto para a economia como para a gestão, compreender por que algumas pessoas trabalham muito enquanto outras 
não, mas que embora respostas simples tenham sido oferecidas, ainda é complexa essa compreensão.

A verdade é que a motivação humana vem despertando interesse e discussões desde o início do século XX. Em meados de 1920, a experiência da Fábrica de Hawthorne, da General Eletric Company, em Chicago, deu início aos experimentos e estudos sobre a influência da motivação e condições de trabalho na produtividade e "ao longo dos tempos, pesquisadores procuram a relação do bom funcionamento e lucratividade nas organizações com a motivação dos colaboradores" (RUFFATTO; PAULI; FERRÃO, 2017, p. 34).

Considerando a importância do assunto, para contribuir com a resolução desse caso para ensino, serão utilizadas duas teorias chave sobre motivação que são basilares e, embora existam outras teorias e autores que abordam o assunto em contextos mais recentes, as duas teorias que apresentam-se na sequência permanecem sendo importantes referenciais teóricos sobre motivação e, portanto, seguem sendo amplamente utilizadas:

\section{$>\quad$ MASLOW}

Abraham Harold Maslow é conhecido internacionalmente pela sua teoria da hierarquia das necessidades, que afirma que os indivíduos aspiram tornarem-se autorrealizados. $\mathrm{O}$ autor também defende que o potencial humano na verdade era um território bastante subestimado e ainda inexplicado (MASLOW, 1970).

Em sua hierarquia, Maslow (1970) afirmava ainda que a motivação das pessoas objetiva satisfazer desde as necessidades mais simples (primárias, fisiológicas), até as necessidades mais complexas ou psicológicas (autorrealização).

Na Tabela 01 é possível observar as hierarquias propostas por Maslow e o que cada uma delas representa.

Tabela 1 - Hierarquia da Necessidade

\begin{tabular}{l|l}
$\begin{array}{l}\text { Tipo de Necessidade } \\
\text { Fisiológica }\end{array}$ & $\begin{array}{l}\text { O que ela representa } \\
\text { A contrapartida da insegurança natural das pessoas: estabilidade, proteção: um } \\
\text { abrigo, uma estrutura, uma ordem, etc. }\end{array}$ \\
\hline Social & $\begin{array}{l}\text { A necessidade endógena de amar e ser amado, ter amizades, vínculos familiares, } \\
\text { intimidade, etc. }\end{array}$ \\
\hline Estima & $\begin{array}{l}\text { A noção das pessoas de se sentirem valorizadas pelos que as rodeiam; sua } \\
\text { autoestima; o desejo de se sentir importante, competente e valorizado. }\end{array}$ \\
\hline Autorrealização & $\begin{array}{l}\text { O desejo dos indivíduos de renovar e reciclar seu potencial; tornar-se cada vez } \\
\text { mais aquilo que deseja, estabelecendo seus próprios desafios/objetivos. }\end{array}$ \\
\hline Fonte: adaptado de Marras (2016) com base na Teoria de Maslow.
\end{tabular}

Para compreender melhor sobre esta hierarquia, Marras (2016) ainda ressalta que as necessidades individuais se diferenciam devido a inúmeras variáveis intrínsecas ou extrínsecas, em que só é possível conseguir a satisfação de uma necessidade de nível superior, quando a inferior tiver sido satisfeita plenamente. Conceito corroborado no estudo de Li, Chen e Hui (2018), quando afirmam que desde Maslow sugere-se que as necessidades de segurança precisam estar satisfeitas para que o indivíduo possa, então, desejar a auto-realização.

Objetivando melhor compreensão sobre o grau de dificuldade de alcance das necessidades psicológicas, essas necessidades são organizadas em uma representação gráfica em formato de pirâmide, conforme apresenta-se na Figura 1. 
Figura 1 - Pirâmide que representa a Hierarquia das Necessidades proposta por Maslow

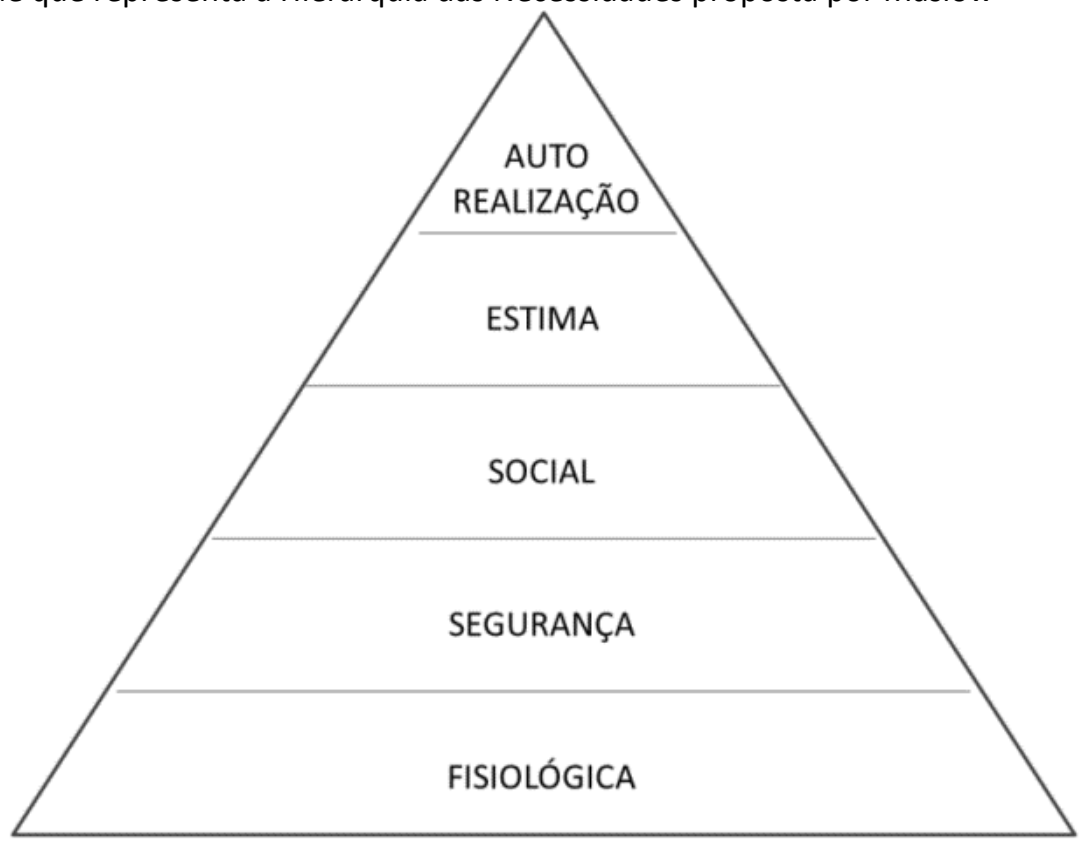

Fonte: representação gráfica da Hierarquia das Necessidades de Maslow (1970).

\section{HeRZBERG}

O professor Frederick Herzberg apresenta a Teoria dos Dois Fatores, formulada em 1959. Baseado em pesquisas empíricas, ele divide os fatores motivadores em dois: motivadores e higiênicos. Alegando que os fatores que indicam satisfação não necessariamente são os mesmos que indicam insatisfação.

Seguindo a teoria de Herzberg, Marras (2016) apresenta, conforme Tabela 02, os fatores motivadores, os fatores higiênicos e suas respectivas determinantes. De acordo com Marras (2016), a presença dos fatores motivadores ou de satisfação geram alto nível de motivação, porém a ausência deles não necessariamente indica desmotivação. Os fatores higiênicos, quando ausentes, proporcionam grande insatisfação, mas sua presença não proporciona o mesmo nível de satisfação que os fatores motivadores.

Tabela 2 - Fatores motivadores ou de satisfação e fatores higiênicos

FATORES MOTIVADORES OU DE SATISFAÇÃO

\begin{tabular}{|c|c|c|c|}
\hline \multicolumn{2}{|c|}{ FATORES MOTIVADORES OU DE } & \multicolumn{2}{|c|}{ FATORES HIGIENICOS } \\
\hline $\begin{array}{l}\text { Fatores } \\
\text { motivadores }\end{array}$ & Determinantes & Fatores higiênicos & Determinantes \\
\hline Realização & $\begin{array}{l}\text { O término com sucesso de um } \\
\text { trabalho ou tarefa; os resultados do } \\
\text { próprio trabalho. }\end{array}$ & Supervisão & $\begin{array}{l}\text { A disposição ou boa vontade de } \\
\text { ensinar ou delegar } \\
\text { responsabilidades aos } \\
\text { subordinados. }\end{array}$ \\
\hline $\begin{array}{l}\text { Reconhecimento } \\
\text { pela realização }\end{array}$ & $\begin{array}{l}\text { O recebimento de um } \\
\text { reconhecimento público, ou não, } \\
\text { por um trabalho bem-feito ou um } \\
\text { resultado conseguido. }\end{array}$ & $\begin{array}{l}\text { Políticas } \\
\text { empresariais }\end{array}$ & $\begin{array}{l}\text { Normas e procedimento que } \\
\text { encerram os valores e crenças da } \\
\text { companhia. }\end{array}$ \\
\hline O trabalho em si & $\begin{array}{l}\text { Tarefas consideradas agradáveis e } \\
\text { que provocam satisfação. }\end{array}$ & $\begin{array}{l}\text { Condições } \\
\text { ambientais }\end{array}$ & $\begin{array}{l}\text { Ambientes físicos e psicológicos } \\
\text { que envolvem as pessoas e os } \\
\text { grupos de trabalho. }\end{array}$ \\
\hline Responsabilidade & $\begin{array}{l}\text { Proveniente de realização do } \\
\text { próprio trabalho ou do trabalho de } \\
\text { outros. }\end{array}$ & $\begin{array}{l}\text { Relações } \\
\text { Interpessoais }\end{array}$ & $\begin{array}{l}\text { Transações pessoais e de trabalho } \\
\text { com os pares, os subordinados e os } \\
\text { superiores. }\end{array}$ \\
\hline
\end{tabular}




\begin{tabular}{|l|l|l|l|}
\hline $\begin{array}{l}\text { Desenvolvimento } \\
\text { pessoal }\end{array}$ & $\begin{array}{l}\text { Possibilidade de aumento de } \\
\text { status, perfil cognitivo ou mesmo } \\
\text { de posição social. }\end{array}$ & Status & $\begin{array}{l}\text { Forma pela qual a nossa posição } \\
\text { está sendo vista pelos demais. }\end{array}$ \\
\hline $\begin{array}{l}\text { Possibilidade de } \\
\text { crescimento }\end{array}$ & $\begin{array}{l}\text { Uma alavancagem dentro da } \\
\text { estrutura organizacional, em } \\
\text { termos de cargo ou } \\
\text { responsabilidades. }\end{array}$ & Remuneração & $\begin{array}{l}\text { O valor da contrapartida da } \\
\text { prestação de serviço. }\end{array}$ \\
\hline & & Vida pessoal & $\begin{array}{l}\text { Aspectos do trabalho que } \\
\text { influenciam a vida pessoal. }\end{array}$ \\
\hline
\end{tabular}

Fonte: adaptado de Marras (2016) com base na Teoria de Herzberg.

Frente às várias necessidades de motivação apresentadas por Maslow e os fatores motivacionais e higiênicos de Herzberg, o caso para ensino leva a refletir sobre a prática destas teorias no dia a dia organizacional da Conexão Criativa.

$\mathrm{Na}$ agência, várias situações podem ser relacionadas a estes aspectos teóricos. $\mathrm{O}$ Quadro 3 auxilia o professor na discussão da alocação dos personagens na Pirâmide das Necessidades, em que " $X$ " significa a hierarquia que o personagem está presente. Nos fatores motivacionais e higiênicos de Herzberg, o quadro aponta como " $\mathrm{P}$ " o que percebe-se presente no personagem e " $A$ " como ausente ou necessidade/carência.

O Quadro 3 oferece, ainda, suporte à aplicação da atividade proposta no Apêndice $2 \mathrm{e}$ às questões 1 e 5 do Apêndice 1 .

Quadro 3 - Enquadramento das necessidades de motivação com base na teoria de Maslow e os fatores motivadores e higiênicos dos personagens, de acordo com a teoria de Herzberg

\begin{tabular}{|c|c|c|c|c|c|}
\hline Teoria & & Tipo/Fator & Paulo & Jéssica & Luís \\
\hline \multirow{5}{*}{ Maslow } & \multicolumn{2}{|l|}{ Fisiológica } & & & \\
\hline & \multicolumn{2}{|l|}{ Segurança } & & & $x$ \\
\hline & \multicolumn{2}{|l|}{ Social } & $x$ & & \\
\hline & \multicolumn{2}{|l|}{ Estima } & & $\mathbf{x}$ & \\
\hline & \multicolumn{2}{|c|}{ Autorrealização } & & & \\
\hline \multirow{13}{*}{ Herzberg } & \multirow{6}{*}{ Motivadores } & Realização & A & $\mathbf{P}$ & A \\
\hline & & Reconhecimento pela realização & A & $\mathbf{P}$ & A \\
\hline & & O trabalho em si & A & $\mathbf{P}$ & A \\
\hline & & Responsabilidade & A & $\mathbf{P}$ & A \\
\hline & & Desenvolvimento pessoal & $\mathbf{P}$ & $\mathbf{P}$ & A \\
\hline & & Possibilidade de crescimento & A & $\mathbf{P}$ & A \\
\hline & \multirow{7}{*}{ Higiênicos } & Supervisão & A & $\mathbf{P}$ & A \\
\hline & & Políticas empresariais & A & A & A \\
\hline & & Condições ambientais & $\mathbf{P}$ & A & $\mathbf{P}$ \\
\hline & & Relações Interpessoais & $\mathbf{P}$ & A & $\mathbf{P}$ \\
\hline & & Status & $\mathbf{P}$ & A & $\mathbf{P}$ \\
\hline & & Remuneração & $\mathbf{P}$ & $\mathbf{P}$ & $\mathbf{P}$ \\
\hline & & Vida pessoal & $\mathbf{P}$ & A & $\mathbf{P}$ \\
\hline
\end{tabular}

Legenda: X - Hierarquia em que se encontra o personagem; P - Presente; A - Ausente.

Fonte: elaborado pelos autores (2019).

Ao mapear e compreender as necessidades dos personagens, bem como os fatores motivadores e higiênicos que estão ausentes, possivelmente se chegará às ações que auxiliarão Jéssica a resolver seu dilema. Observa-se que Jéssica, não diferentemente de Luís, também possui necessidades e fatores de realização que não estão sendo supridos, fato que pode desencadear desmotivação contagiosa que refletiria no trabalho de toda a equipe.

Por outro lado, o inverso também é verdadeiro, ou seja, ao ir suprindo suas próprias necessidades e fatores motivadores e sabendo conduzir Luís para sua motivação profissional, 
adotando com ele o melhor estilo de liderança de acordo com cada situação estabelecida, Jéssica pode obter melhores resultados junto a toda sua equipe e, por consequência, melhorar o clima organizacional da Conexão Criativa.

\section{REFERÊNCIAS}

AVOLIO, B. J.; WALUMBWA, F. O.; WEBER, T. J. Leadership: current theories, research, and future directions. Annual Review of Psychology, v. 60, p. 421-449, 2009. DOI: 10.1146/annurev.psych.60.110707.163621.

CASTRO, P. K. L. B.; SILVA, S. M. V. Liderança organizacional em uma incubadora de empresas de base tecnológica. Revista Navus, Florianópolis, v. 7, n.3, p. 71-85, 2017. DOI: https://doi.org/10.22279/navus.2017.v7n3.p71-85.478.

CINTRA, J.; DALBEM, E. Comportamento organizacional. Londrina: Editora e Distribuidora Educacional S.A., 2016.

DIAS, M. A. M. J.; BORGES, R. S. G. Estilos de liderança e desempenho de equipes no setor público. Revista Eletrônica de Administração - REAd, Porto Alegre, v. 80, n 1, p. 200-221, jan./abr., 2015. DOI: http://dx.doi.org/10.1590/1413-2311.0542014.53468.

FONSECA, A. M. O.; PORTO, J. B.; BORGES-ANDRADE, J. E. Liderança: um retrato da produção científica brasileira. Revista de Administração Contemporânea, Rio de Janeiro, v. 19, n. 3, p. 290-310, 2015. DOI: http://dx.doi.org/10.1590/1982-7849rac20151404.

GONCALVES, H. S.; MOTA, C. M. M. Liderança situacional em gestão de projetos: uma revisão da literatura. Produção, São Paulo, v. 21, n. 3, p. 404-416, 2011. DOI: http://dx.doi.org/10.1590/S0103-65132011005000046.

HAECKL, S.; SAUSGRUBER, R.; TYRAN, J. R. Work Motivation and Teams. SSRN Eletronic Journal, 2018. DOI: http://dx.doi.org/10.2139/ssrn.3239948.

HERSEY, P.; ANGELINI, A. L.; CARAKUSHANSKY, S. The impact of situational leadership and classroom structure on learning effectiveness. Group and Organization Studies, v. 7, p. 216224, 1982. DOI: https://doi.org/10.1177/105960118200700209.

LEENDERS, M. R.; MAUFFETTE-LEENDERS; L. A.; ERSKINE, J. A. Writing cases. 4th. London: Richard Ivey School of Business, 2001.

LEWIN, K. Field theory in social science: selected theoretical papers. California: Greenwood Pub Group, 1951.

LI, Z.; CHEN, Z.; HUI, Y. Portfolio selection through Maslow's need hierarchy theory. Applied Economics, v. 50, p. 364-372, 2018. DOI: 10.1080/00036846.2018.1496223

MASLOW, A. H. Maslow no gerenciamento. Rio de Janeiro: Qualitymark, 2001. 
MARRAS, J. P. Administração de recursos humanos: do operacional ao estratégico. 15. ed. São Paulo: Saraiva, 2016.

OLIVEIRA, F. B.; SANT'ANNA, A. S.; DINIZ, D. M.; CARVALHO NETO, A. M. Leaderships in urban contexts of diversity and innovation: the Porto Maravilha Case. Brazilian Administration Review, Rio de Janeiro, v. 12, n. 3, p. 268-287, 2015. DOI: http://dx.doi.org/10.1590/1807-7692bar2015140080.

POLICARPO, R. V. S.; BARROS, R. S. G. Mudança organizacional: os efeitos dos estilos de liderança no comportamento dos trabalhadores. Economia e Gestão, Belo Horizonte, v. 16, n. 45, out./dez., 2016. DOI: https://doi.org/10.5752/P.1984-6606.2016v16n45p78.

PUTRA, E. D.; CHO, S. Characteristics of small business leadership from employees' perspective: a qualitative study. International Journal of Hospitality Management, v. 78, p. 36-46, 2019. DOI: https://doi.org/10.1016/j.ijhm.2018.11.011.

REIS, T. A.; BRUGNEROTTO, T. R.; SEVILHA, I. C.; CREMONEZI, G. O. G.; -OSWALDO, Y. C. Endomarketing, liderança e comunicação: reflexos na organização. Revista Brasileira de Marketing - ReMark, v. 17, n. 1, 2018.

RUFFATTO, J.; PAULI, J.; FERRÃO, A. R. Influência do estilo de liderança na motivação e conflitos interpessoais em empresas familiares. Revista de Administração FACES Journal, Belo Horizonte v. 16 n. 1, 2017. DOI: http://dx.doi.org/10.21714/19846975FACES2017V16N1ART3616.

SOUSA, M. J.; ROCHA, A. Leadership styles and skills developed through game-based learning. Journal of Business Research, v. 94, p. 360-366, 2019. DOI: https://doi.org/10.1016/j.jbusres.2018.01.057.

TURANO, L. M.; CAVAZOTTE, F. Conhecimento Científico sobre Liderança: uma análise bibliométrica do acervo do The Leadership Quarterly. Revista de Administração Contemporânea, Rio de Janeiro, v. 20, n. 4, p.434-457, 2016.DOI: http://dx.doi.org/10.1590/1982-7849rac2016140075. 
Um pessimista convicto na minha equipe: estilos de liderança e motivação

\section{APÊNDICE 1 - Sugestão de Questionário para aplicação individual}

1. A Teoria das Necessidades Hierárquicas de Maslow possui cinco categorias. Assinale a alternativa que contém as cinco categorias corretas:

( ) Higiênicas, motivadoras, de segurança, de estima, sociais e de autorrealização.

( ) Fisiológicas, de segurança, de desempenho, de estima e de autorrealização.

( ) Higiênicas, de segurança, sociais, de esforço e de autorrealização.

( ) Fisiológicas, de segurança, sociais, de estima e de autorrealização.

( ) Motivadoras, de segurança, de desempenho, de esforço e de autorrealização

2. Descreva detalhadamente qual é o estilo de liderança de seu superior na empresa onde você trabalha ou de algum líder de sua família.

3. Com qual dos tipos de liderança discutidos anteriormente você se adaptaria melhor no seu dia a dia de trabalho?

4. Você acabou de se tornar líder de uma grande equipe em uma multinacional e tem total liberdade para adotar seu estilo de liderança. O que e como faria para ser um líder que busca auxiliar sua equipe a manter-se motivada?

5. Considerando a Teoria dos Dois Fatores proposta por Herzberg e pensando em sua atual experiência profissional ou pessoal, liste quais são os fatores motivadores presentes em seu cotidiano e quais são os fatores higiênicos ausentes em seu cotidiano. Explique de que forma isso impacta seu desempenho.

Fonte: adaptado de Cintra e Dalbem (2016).

RGO - Revista Gestão Organizacional, Chapecó, v. 14, n. 2, p. 06-24, maio/ago. 2021. 
Francine Lucatelli, João Anselmo Tormen-Ferreira, Anete Alberton e Sidnei Vieira Marinho

\section{APÊNDICE 2 - Sugestão de atividade em grupo}

Identifique, no Caso para Ensino, personagens e situações que condizem com as necessidades elencadas por Maslow:

AUTORREALIZAÇÃO

ESTIMA

SOCIAL

SEGURANÇA

FISIOLÓGICA

Fonte: adaptação da representação gráfica da Hierarquia das Necessidades de Maslow (1970). 